\title{
Penerapan Metode SDLC RUP (Rational Unified Proses) Dalam Pembuatan Sistem Informasi E-kos Berbasis Web
}

\author{
Sandy Young ${ }^{*}$, Ilyas Nuryasin ${ }^{2}$, Wildan Suharso ${ }^{3}$ \\ 1,2,3 Teknik Informatika/Universitas Muhammadiyah Malang \\ sandy_437116@webmail.umm.ac.id ${ }^{* 1}$, Ilyas.nuryasin@gmail.com ${ }^{2}$
}

\begin{abstract}
Abstrak
Sistem informasi saati ini semakin berkembang pesat. Teknologi di era sekarang sangat membantu semua orang agar lebih mudah dan lebih efektif penggunaannya. Termasuk didalamnya untuk membantu pemilik kost untuk menyebarkan info tentan indekosnya dan mahasiswa untuk mencari tempat indekos terdekat dengan kampus. Kebutuhan akan indekos yang sangat penting bagi mahasiswa yang melakukan studi dalam waktu yang lama dan membutuhkan tempat tinggal. Website indekos ini akan menggunakan Rational Unified Process (RUP) sebagai metode pengembangan sistem untuk membangun website ini. Dari permasalahan yang ada, maka di dapat topik yang dapat diangkat menjadi bahasan dengan judul "Penerapan Metode SDLC RUP (Rational Unified Proses) Dalam Pembuatan Sistem Informasi E-kos Berbasis Web". Rational Unified Process memiliki 4 fase yaitu inception, elaboration, Construction, Transition dan disetiap fase memiliki tugasnya masing-masing [1]. Inovasi tersebut dapat mempermudah mahasiswa mencari tempat indekos dan membantu pemilik indekos untuk membantu mempromosikan kostnya serta informasi infokosnya yang detail.
\end{abstract}

Kata Kunci: RUP, Rational Unified Process, Inception, Elaboration, Construction, Indekos

\begin{abstract}
System information system is growing rapidly. Technology in the present era really helps everyone to make it easier and more effective to use. Login to help the owner to find out information about his boarding house and students to find the place of residence closest to campus. The need for homestay is very important for students who study for a long time and need a place to live. This website will use Rational Unified Process (RUP) as a system development method for building this website. From there, the topic can be discussed with the title "Penerapan Metode SDLC RUP (Rational Unified Proses) Dalam Pembuatan Sistem Informasi E-kos Berbasis Web". Rational Unified Process has 4 phases, namely inception, elaboration, construction, transition and each phase has their respective tasks. This innovation can make it easier for students to find homestays and help homestay owners to help promote their boarding and detailed infocos information.
\end{abstract}

Keywords: RUP, Rational Unified Process, Inception, Elaboration, Construction, Indekos, Kost

\section{Pendahuluan}

Sistem informasi merupakan cara menyajikan informasi maupun data yang terkait dengan kebutuhan peneriman informasi. Bertujuan untuk meberikan sebuah informasi dalam bentuk perancanaan, pengoganisasian maupun sistem penentu keputusan. Dalam perkembangannya penerimaan informasi pengalaman percepatan yang signifikan, yang disebabkan oleh percepatan arus teknologi informasi dan internet. Perkembangan tersebut menjadi suatu dasar peneliti untuk membuat sebuah sistem informasi yang dinamis dan serta mudah diakses oleh pengguna [2].

Sistem informasi tersebut, peneliti menerapkan studi kasus Indekos tersebut berlatar belakang dari permasalahan mahasiswa yang mempunyai permasalahan dalam mencari kamar kost. Karena minimnya informasi letak kost, fasilias kost, ketersediaan kamar kost dan harga kost. Selain itu pemilik kost terlalu pasif dalam menyebarkan informasi tentang kamar kost[3]. Sehingga menimbulkan kebingungan antara pembeli dan penyedia kamar kost. Penerapan sistem informasi pada indekost diharapkan mempermudah mahasiswa untuk mencari ketersediaan kamar dan penyedia kamar kost untuk pemasaran.

Indekost pada website infokost.com memiliki kekurangan pada bagian tertentu, seperti halnya harga kost per kamar tidak ditampilkan, tidak disebutkan fasilitas yang didapat dan 
ketersediaan kamar, serta dan aturan yang berlaku pada tempat kost tersebut. Dari beberapa permasalahan tersebut, maka diperlukan adanya perubahan terhadap sistem E-kost dengan menggunakan metode RUP (Rational Unified Proses) agar sistem yang dibangun sesuai dengan kebutuhan. Tujuan pengembangan sistem adalah menghasilkan sebuah sistem yang dapat mempermudah mahasiswa mencari tempat kost dan mempermudah pemilik kost untuk mengiklankan kostnya.

RUP (Rational Unified Proses) adalah pendekatan pengembangan perangkat lunak yang dilakukan berulang-ulang,fokus pada arsitektur, lebih diarahkan berdasarkan penggunaan kasus. Dimana metode ini memiliki dua dimensi, dimensi pertama mewakilkan waktu dan menunjukan aspek dinamis dari pengembangan perangkat lunak, dimensi ini terdiri dari empat tahapan yaitu inception, elaboration, construction dan transition. Dimensi kedua mewakili aspek- aspek statis dari proses pengembangan perangkat lunak yang dikelompokkan ke dalam beberapa disiplin terdiri dari Business Modeling, Requirement, Analysis and Design, Implementasi Test dan Deployment [2]. Diharapkan sistem informasi dapat menghasilkan sebuah sistem informasi yang lebih baik dan sesuai dengan harapan.

\section{Metode Penelitian}

\subsection{Rational Unified Process}

Metode Rational Unified Process adalah Pendekatan atau pengembangan sebuah perangkat lunak yang dilakukan secara berulang-ulang (iterative) focus terhadap arsitektur, lebih diarahkan berdasarkan penggunaan kasus (use case driven). RUP sendiri menggunakan iterative incremental sebagi model siklus pengembangan aplikasi. Model ini membagi suatu sistem yang sangat memungkinkan bagi para prengembang aplikasi untuk menerapkan metode tersebut terhadap komponen [4]. Dalam metode tersebut ini,terdapat empat fase pengembangan yang harus dilakukan bila menggunakan metode RUP ini, 4 fase tersebut diantaranya fase 4 fase diantaranya :

\section{a. fase inception}

Fase inception dimana tahap ini melakukan permodelan bisnis yang dibutuhkan (business modeling) dan menganalisis kebutuhan fungsional dan kebutuhan nonfungsional (Requirment)[4].

\section{b. elaboration}

Fase elaboration tahap dimana lebih memfokuskan pada perancanaan dan arsitektur sistem tahap ini lebih pada analisis dan desain sistem[4].

\section{c. Construction}

Fase construction Tahap setelah melakakukan fase elaboration dimana proses menerjemahkan desain dalam pengembangan sistem. Kegiatan dalam pengembangan pada tahap ini mencari template yang sesuai dengan mock up yang sudah dibuat, membuat daftar urutan pengembangan,membangun sistem informasi menggunakan pemogramman PHP dan MySQL sebagai databasenya[4].

\section{d. Transition}

Di tahap transition tahap dimana melakukan (deployment) atau melakukan instalasi sistem agar dapat dimengerti dan dipahami pengguna. Aktifitas pada tahap transition ini melakukan pelatihan user dan pemeliharaam system[4].

\subsection{Business Model Canvas}

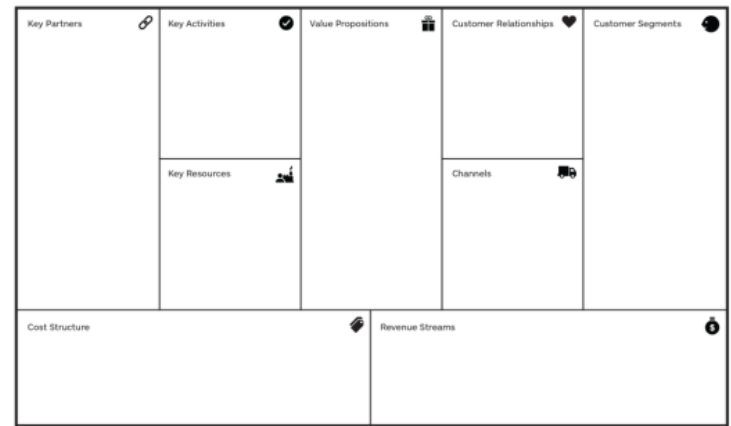

Gambar 1. Tampilan Bisnis Model Canvas

REPOSITOR, Vol. 2, No. 3, Maret 2020: 363-372 
Menurut Osterwalder \& Pigneur dalam sebuah buku "Business Model Generatioan" bisnis model canvas adalah model bisnis yang berisi 9 blok area aktivitas bisnis, dimana memiliki tujuan menentukan strategi untuk membangun sebuah bisnis yang kuat, bisnis model canvas ini memiliki cirikhas dengan 9 blok model yang jika di disatukan akam nejadi satu kesatuan bisnis. Adapun sembilan blok tersebut [5]. Dimana 9 blok tersebut membantu seseorang untuk bisa membangun sebuah produk yang tepat. Gambar 1 berikut adalah template bisnis Model canvas.

Dari pembahasan di atas dapat kesimpulan bisnis model canvas sangat membantu seseorang untuk memulai bisnis dimana membuat suatu produk harus jelas dan kuat. dimana pemilik bisnis harus memiliki 9 blok tersebut agar bisnisnya berjalan dengan baik dan mengurangi tingkat kegagalan dalam berbisnis [5].

\section{Hasil Penelitian dan Pembahasan \\ 3.1 Fase Inception \\ 3.1.1 Business Model Canvas}

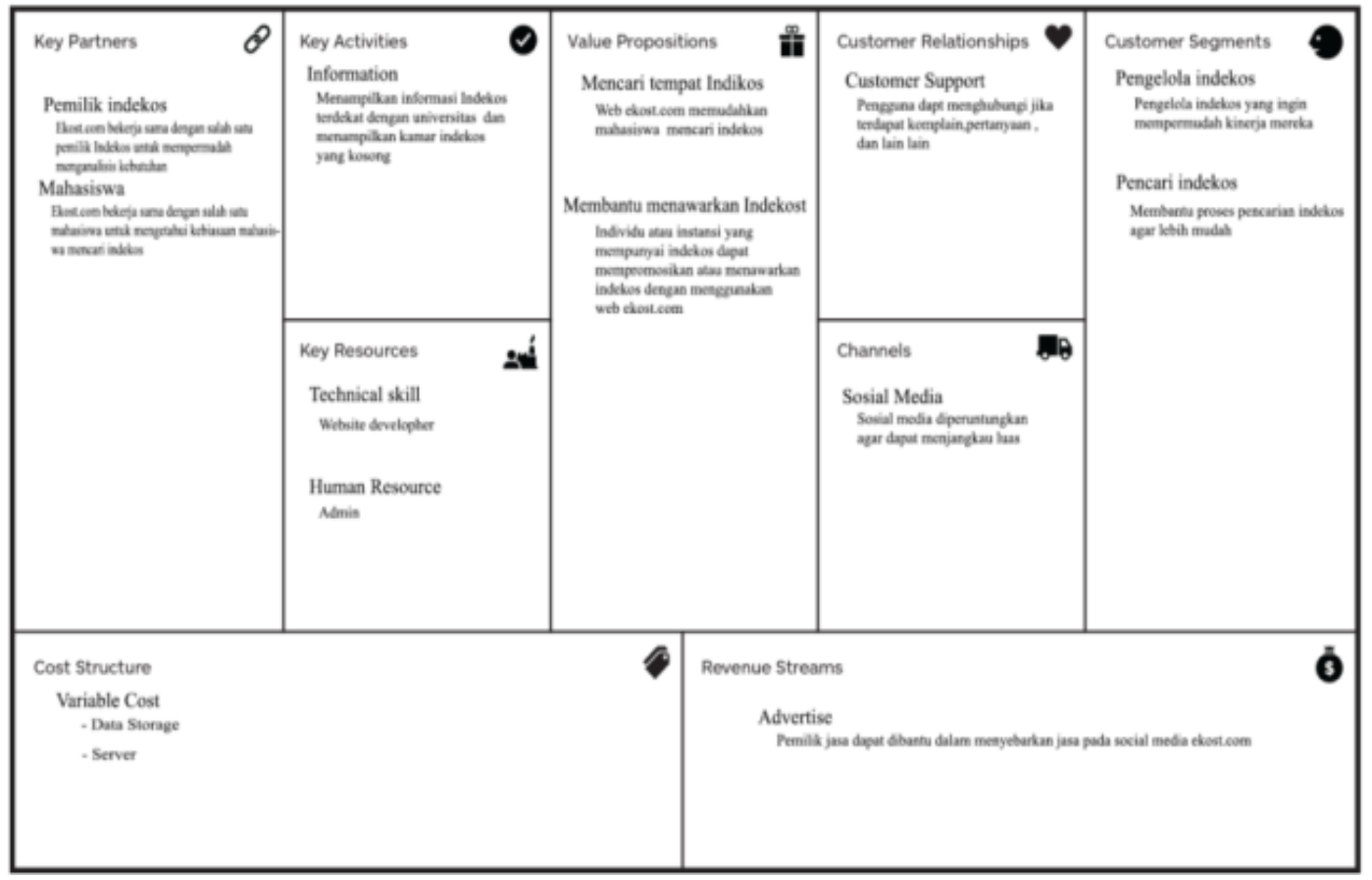

Gambar 2. Business Modeling Canvas Indekos

Value Proposition dalam penelitian ini membuatkan sebuah web ekost.com yang dimana membantu pemilik indekos untuk mempromosikan atau memberi informasi tentang harga kamar, kamar yang kosong, fasilitas apa aja yang ada, peraturan apa aja yang ada di indekos, alamat ,dan di daerah kampus mana

Key Activites dalam penelitian ini memiliki kegiatan utama yaitu membuat sebuah sistem untuk membantu pemilik kost untuk mempromosikan indkosnya atau memberi informasi indekosnya kepada mahasiswa baru dan membantu mahasiswa untuk mengetahui informasi tentang indekosnya.

Key Resource dalam penelitian membuat dan memelihara aplikasi perlu adanya human resource dan web developer untuk membuat dan memelihara aplikasi web ini agar dapat berjalan dengan baik. Selain itu perlu nya admin untuk menjawab hal-hal yang ditanyakan oleh pengguna. Kebutuhan akan server sangat penting untuk menyimpan data dari pengguna ataupun segala aktivitas yang dilakukan dalam web.

Key Partners dalam penelitian ini untuk menyukseskan web ekost.com, Dibutuhkan kerja sama dengan pemilik indekos dan mahasiswa sehinnga mempermudah menganalisis kebutuhan dan mereka mau menggunkan aplikasi ini. Selain itu pula untuk meninggkatkan kesadarkan pemilik indekos dan mahasiswa akan adanya web ini. 
Channels dalam penelitian ini Untuk mempromosikan web ekost.com dengan social media seperti Instagram,twitter,dan facebook untuk melakukan promosi agar orang-orang mengetahui web ekost.com dan menggunakan organisasi kampus untuk mengarahkan mahasiswa baru untuk menggunakan web ekost.com untuk mencari indekos tanpa harus kesusahan.

Customer Segments dalam penelitian ini adalah pemilik indekos yang memiliki kesibukan setiap harinya membuka pintu dan menjelaskan aturan,harga, fasilitas-fasilitas danmenunjukan kamar yang kosong berulang kali tentang Indekostnya. Selain itu bagi mahasiswa baru yang masih belum tahu jalan harus tanya seseorang untuk mencari indekos juga harus

menghampiri tiap rumuh pemilik indekos untuk menanyakan aturan, harga setiap kamar, fasilitas-fasilitas dan kamar mana yang kosong berulang kali di setiap masing masing indekos

Customer relationship dalam penelitian ini Untuk menjaga hubungan dengan pengguna aplikasi, peneliti menggunakan dua cara yaitu dengan adalah dengan customer service. Customer service dapat membantu pengguna aplikasi jika memilki kesusahan ataupun pertanyaan dengan mengirimkan email ke customer service.

Cost Structure dalam penelitian untuk menjaga Business ini tetap berjalan terbagi menjadi dua bagian yaitu variable cost. Variable cost merupakan biaya yang nilai nya dapat berubahubah. Dari Business ini, variable cost yang dimiliki adalah data storage atau server.

Revenue Streams dalam penelitian ini memiliki satu bagian utama membuka lowongan untuk iklan di web ekost.com dan disebarkan pada social media milik ekos.com sehingga dapat meningkatkan kesadaran mahasiswa baru untuk mencari kost melalui ekost.com.

\subsubsection{Requirement}

Kebutuhan fungsional yang berisi kebutuhan/fitur apa saja yang diinginan dan ini harus ada atau bisa dikatakan fitur utama. Tabel 1 berikut adalah tabel kebutuhan fungsional.

Tabel 1. Tabel Kebutuhan Fungsional

\begin{tabular}{cc}
\hline No & Kebutuhan Fungsional \\
\hline 1 & User/mahasiswa yang ingin mencari kost dipermudah \\
2 & Pemilik kost bisa menambahkan kamar \\
3 & Pemilik kost bisa menghapus kamar \\
4 & Pemilik kost bisa melakukan pengeditan kamar \\
5 & Pemilik kost bisa menambahkan fasilitas umum yang ada \\
6 & Pemilik kost bisa menghapus fasilitas umum yang ada \\
7 & Pemilik kost bisa mengedit fasilitas umum yang ada \\
8 & Pemilik kost bisa menambahkan fasilitas tambahan yang ada \\
9 & Pemilik kost bisa menghapus fasilitas tambahan yang ada \\
10 & Pemilik kost bisa mengedit fasilitas tambahan yang ada \\
11 & Pemilik kost bisa menambahkan peraturan yang ada \\
12 & Pemilik kost bisa menghapus peraturan yang ada \\
13 & Pemilik kost bisa mengedit peraturan ada \\
14 & Pemilik kost bisa mengedit biodata \\
\hline
\end{tabular}

Pada Tabel 2, kebutuhan non fungsional yang berisi kebutuhan/fitur apa saja yangdiinginkan tapi tahap ini tidak memberatkan perilaku yang diinginan oleh sistem.

Tabel 2. Tabel Kebutuhan Non Fungsional

\begin{tabular}{cc}
\hline No & Non Fungsional \\
\hline 1 & Tampilan yang mempermudah pencari kost \\
2 & Tampilan yang lebih simple dan mudah dipahami oleh pemilik kost \\
3 & Sistem dapat dijalankan oleh beberapa software web browser \\
diantaranya Internet Explore, Google Chrome dan Mozilla Firefox.
\end{tabular}

\subsubsection{Analisis dan Desain}

Analisis dan desain di fase inception untuk mempermudah menuju ke fase elaboration sudah mengetahui format yang di inginkan. Gambar 3 berikut adalah bagian dari usecase indekos yang ingin dibuat.

REPOSITOR, Vol. 2, No. 3, Maret 2020: 363-372 


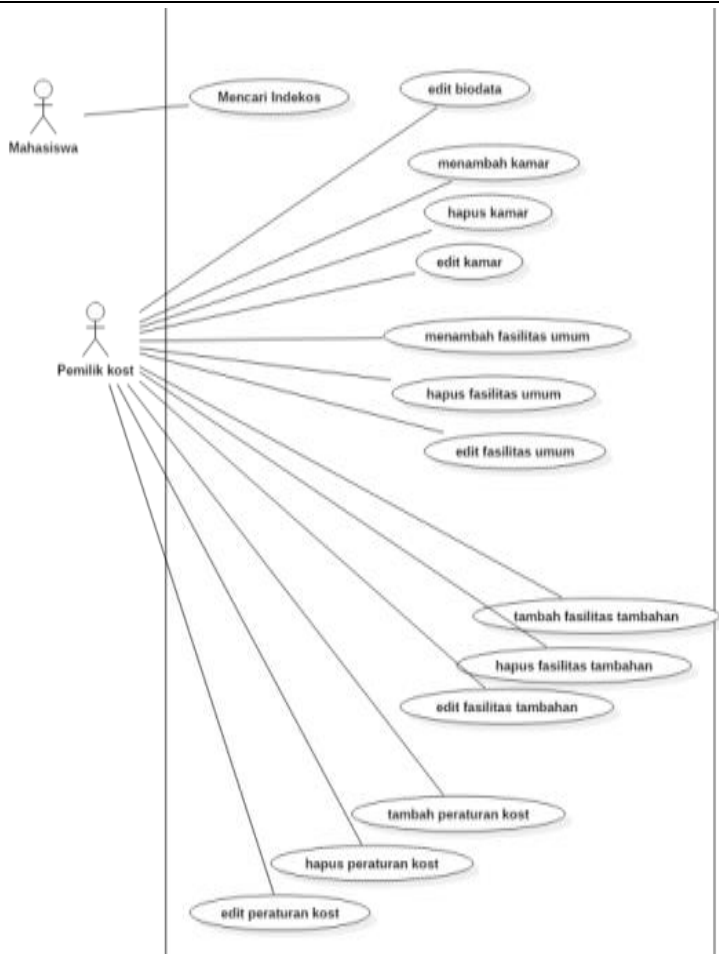

Gambar 3. Usecase Diagram

\subsection{Fase Elaboration}

\subsubsection{Business Model Canvas}

Bisnis modeling yang akan dilakukan adalah menjelaskan tentang keuangan yang dimana di bisiness Modeling canvas yaitu cost Structure dan Reveuie Streams. Tabel 3 Cost Structure adalah kebutuhan yang dibutuhkan untuk membuat sebuah sistem informasi tersebut

Tabel 3. Cost Structure

\begin{tabular}{ccc}
\hline No & Kebutuhan & Harga \\
\hline 1 & Hosting & Rp. 500.000 \\
2 & Domain & Rp. 500.000 \\
\hline
\end{tabular}

Revenue Streams pada Tabel 4 menjelaskan tentang penghasilan yang didapat dari sistem yang akan dibuat.

Tabel 4. Reveneu Streams

\begin{tabular}{ccc}
\hline No & Keuntungan & Harga \\
\hline 1 & Iklan (1-5) & Rp. 30.000/minggu \\
2 & Iklan(6-20) & Rp. 20.000/minggu \\
\hline
\end{tabular}

\subsubsection{Requirement}

Di requerment mengalami penambahan di kebutuhan fungsional. Di fase elaboration ini mengalami penambahan 2 kebutuhan fungsional seperti yang ditunjukkan pada Tabel 5 .

Tabel 5. Kebutuhan Fungsional terbaru

\begin{tabular}{cc}
\hline No & Kebutuhan Fungsional \\
\hline 1 & Admin bisa melakukan hapus kost \\
2 & Admin bisa mengedit semua kost \\
& yang sudah terdaftar \\
\hline
\end{tabular}

\subsubsection{Analisis dan Desain}

Use case menggambarkan secara ringkas siapa aktornya dan aktvitas apa aja yang dilakukan oleh aktor. Gambar 4 berikut merupakan tampilan usecase diagram website indekos. 


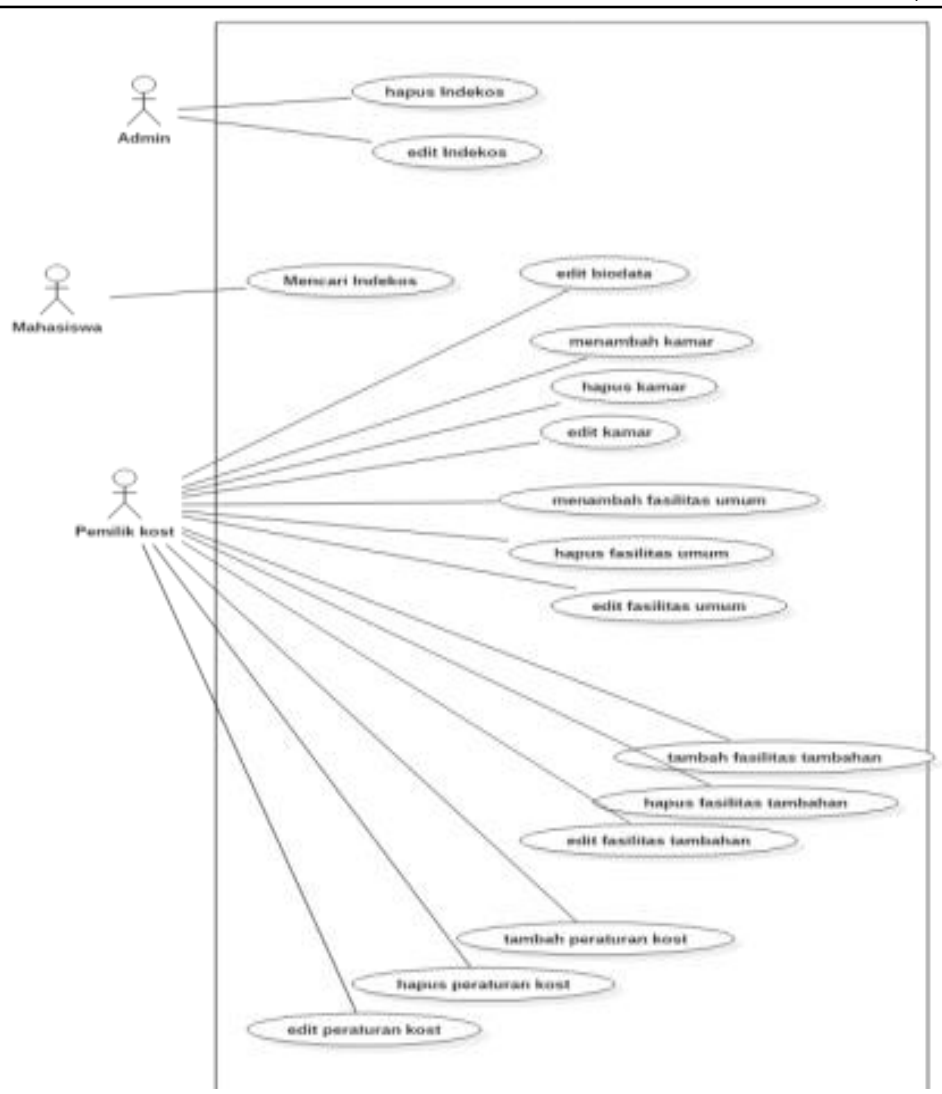

Gambar 4. Usecase Diagram Indekos

Gambar 5 berikut ini melakukan pengembangan dari use case diagram yang dimana menjelaskan setiap kegiatan yang akan dilakukan oleh aktor. Pengembangannya berbentuk scenario, activity diagram dan sequence diagram di website indekos. Berikut pengembangan yang dilakukan.

Setelah selesai membuat semua scenario, activity diagram dan sequence diagram setelah itu lanjut mengerjakan desain database. Setelah Melakukan desain database lalu membuat mock up.

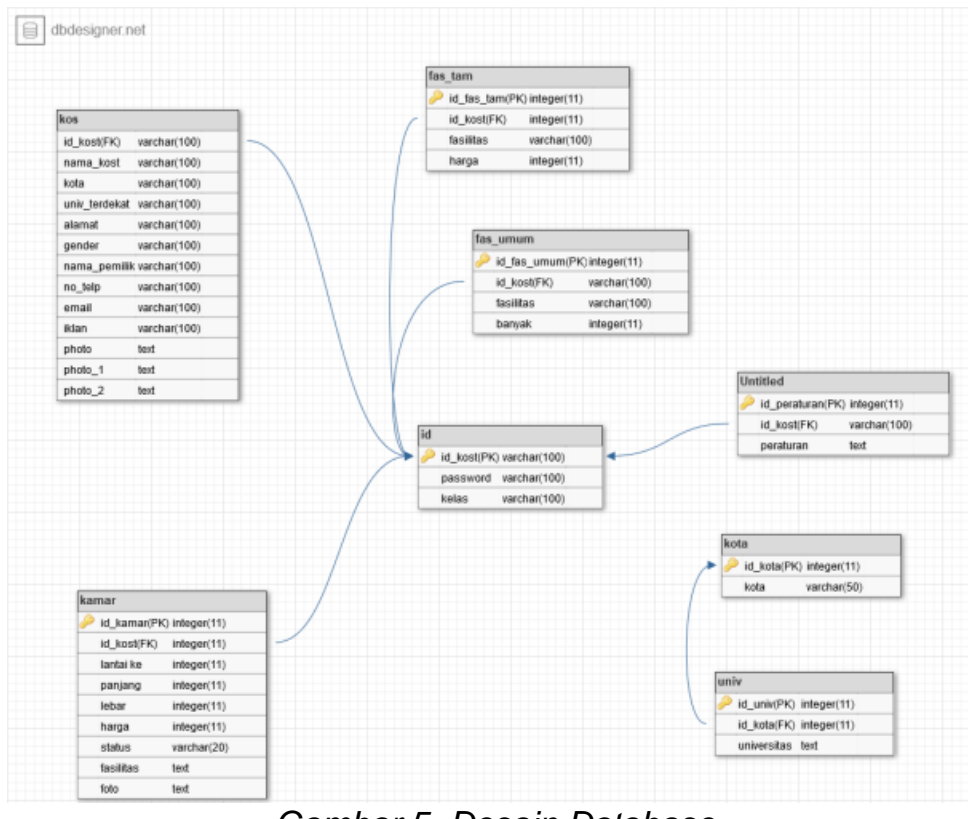

Gambar 5. Desain Database

REPOSITOR, Vol. 2, No. 3, Maret 2020: 363-372 


\subsubsection{Implementasi}

Menyesuaikan mock up dengan template yang sudah di pilih. Bisa dilihat dibawah sebagian tamplate yang sudah jadi.

\subsection{Fase Contruction}

\subsubsection{Implementasi}

Ditahap implementasi menampilkan screenshot website yang telah dibuat. Berikut screenshot dari website indekos.

\section{a. Home Page}

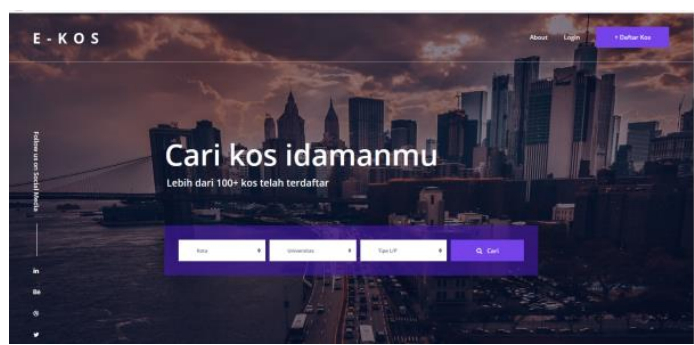

Gambar 6. Home Page

Gambar 6 merupakan halaman pertama kali akan dijalankan pada saat membuka web tersebut pencari kos harus mengimputkan kota universitas calon mahasiswa dan jenis kos kosan laki laki atau perempuan.

\section{b. Hasil Pencarian}

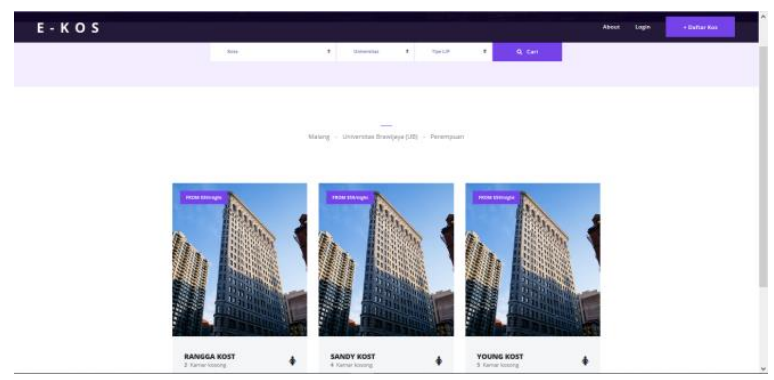

Gambar 7. Hasil Pencarian

Pada Gambar 7, halaman ini merupakan hasil dari pencarian calon mahasiswa atau pencari Indekos untuk melakukan survey harga kamar dan fasilitas yang di inginkan. Agar pada saat datang ke Indekos tinggal melakukan pembayaran.

\section{c. Lihat Indekos}

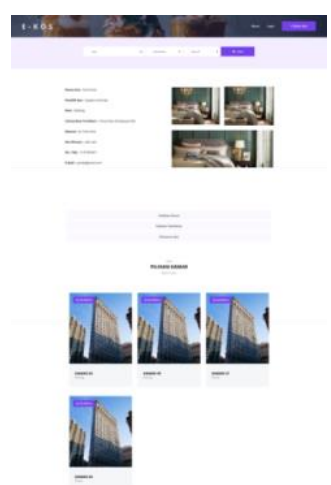

Gambar 8. Lihat Indekos 
Pada Gambar 8, halaman ini merupakan melihat tampilan Indekos secara detail dari kamar, biodata indekos fasilitas umum, fasilitas tambahan, juga mengetahui kamar yang kosong. Perbedaan fasilitas umum dan fasilitas tambahan yang dimana fasilitas umum fasilitas yang bisa dipakai semua penyewa Indekos dan fasilitas tambahan yang dimana harus membayar perbulannya.

\section{d. Lihat Kamar}

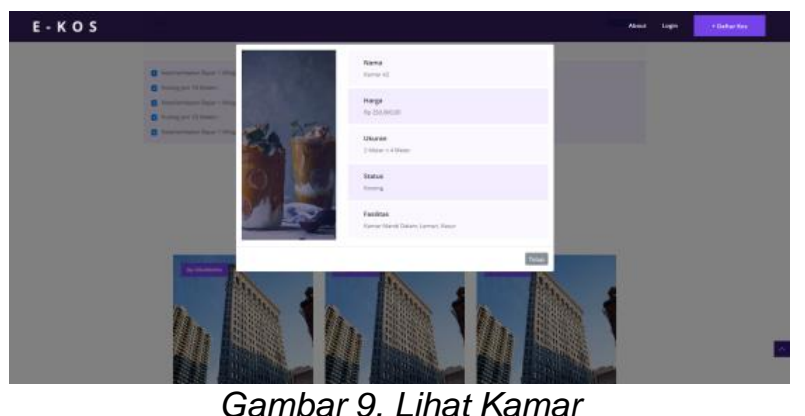

Pada Gambar 9, halaman ini muncul jika mengklik kamar secara detail dengan mengklik kamar yang di inginkan. Jika di klik maka muncul popup yang berisikan nama kamar, lanti, ukuran kamar, harga, fasilitas kamar.

\section{e. Pendafaran Indekos}

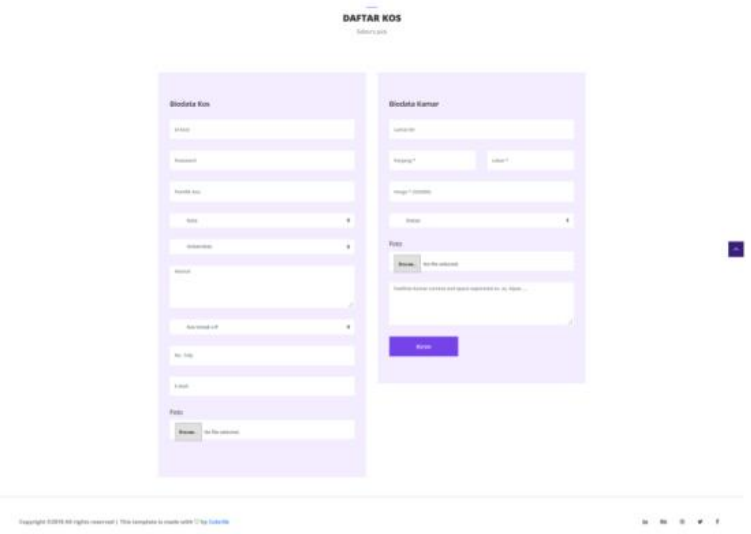

Gambar 10. Pendaftaran Indekos

Pada Gambar 10 ini merupakan awal dimana pemilik Indekos mendaftarkan Indekosnya agar bisa di publish.

\subsubsection{Testing}

Testing disini saya menggunakan metode black box testing yang dimana setelah di uji sudah sesesuai dengan apa yang di inginkan

Pada bab ini berisikan tentang kesimpulan dari hasil penelitian pembuatan aplikasi kosanku dan terdapat saran untuk pengembangan topik tugas akhir yang sejenis.

\section{Kesimpulan dan Saran}

\subsection{Kesimpulan}

1. Berdasarkan penelitian tersebut yang sudah dilakukan bahwa rancang bangun ekost bisa diterapkan dengan menggunakan Rational Unified Process.

2. Rational Unified Process bisa diterapkan dengan menggunakan single developer.

3. Pembangunan Ekos sudah di uji coba dan sesuai dengan yang di harapkan peneliti.

REPOSITOR, Vol. 2, No. 3, Maret 2020: 363-372 


\subsection{Saran}

1. Uji lebih lanjut efektivitas single developer untuk project project besar.

\section{Referensi}

[1] R. Andrian and M. Chairuddin, "Pengembangan Sistem Informasi Penelitian dan Pengabdian Dosen Jurusan IImu Komputer Menggunakan Metode Rational Unified Process ( RUP )," pp. $1-8$.

[2] U. Ependi, Y. N. Kunang, S. Novifika, J. Ahmad, and Y. No, "Implementasi Metode Rational Unified Process Pada Mobile Digital Library," no. 3, pp. 35-44

[3] T. K. Bakti Abidin, Ira Prasetyaningrum, "Sistem Informasi Rumah Kost Online Berbasis Web Dan Messaging," Sist. Inf. Rumah Kost Online Berbas. Web dan Messag. Bakti, pp. 1-11, 2012.

[4] Alexander Osterwalder and Yves Pigneur (2012). Business Model Generatio

[5] S. Susilowati and R. R. Aria, "Implementasi Metode Rational Unified Process Penjualan Alat Telekomunikasi Berbasis Website," pp. 89-95, 2015. 
REPOSITOR, Vol. 2, No. 3, Maret 2020: 363-372 